\title{
Penerapan iptek melalui kukerta terintegrasi guna mengakselerasi pengembangan wisata bahari di Kelurahan Kampung Baru, Kecamatan Senapelan, Kota Pekanbaru
}

\author{
Muhammad Fauzi ${ }^{* 1}$, Eko Prianto ${ }^{1}$, Budijono ${ }^{1}$, Iskandar Putra ${ }^{1}$, Muhammad Farhan Surez ${ }^{2}, \&$ \\ Zuriati Murni ${ }^{1}$
}

${ }^{1}$ Fakultas Perikanan dan Kelautan, Universitas Riau

${ }^{2}$ Fakultas Ilmu Sosial dan Ilmu Politik, Universitas Riau

*m.fauzi@lecturer.unri.ac.id

\begin{abstract}
Abstrak. Kampung Baru merupakan salah satu kelurahan di Kota Pekanbaru yang memiliki potensi pengembangan wisata bahari yang besar. Letaknya yang strategis di pesisir Sungai Siak dan memiliki cagar budaya "Rumah Batin" menjadikan Kampung Baru sebagai salah satu destinasi baru wisata sejarah kedepannya. Keberadaan Kampung Baru sebagai destinasi wisata masih belum terekspos dengan baik sehingga perlu adanya sentuhan Iptek dan pembenahan untuk mengakselerasi pengembangannya. Tujuan kegiatan ini adalah untuk mengakselerasi pengembangan wisata bahari di Kelurahan Kampung Baru Kota Pekanbaru. Metode yang digunakan adalah metode survey untuk mengidentifikasi kegiatan dan metode penyuluhan untuk menyampaikan Iptek kepada masyarakat. Tahapan pelaksanaan kegiatan dibagi menjadi tiga yaitu tahapan persiapan, pelaksanaan dan evaluasi. Hasil survey cepat yang dilaksanakan, untuk mengakselerasi pengembangkan kegiatan wisata bahari di Kampung Baru melalui sosialisasi sertifikat halal, membuat dan membagi tempat sampah, pembuatan dan menegakan papan plang, penanaman pohon dan bibit sayur dan pembersihan rumah batin. Pelaksanaan kegiatan tersebut berjalan dengan baik dan tepat sasaran hal ini dapat dilihat dari animo masyarakat dan aparat kelurahan dalam mendukung kegiatan ini. Dengan adanya KUKERTA terintegrasi ini potensi wisata Kampung Baru yang terabaikan mampu diangkat kembali sebagai wisata bahari. Ini menujukkan bahwa sentuhan Iptek melalui KUKERTA terintegrasi mampu mengakselerasi pengembangan wisata bahari di Kampung Baru.
\end{abstract}

Kata kunci: wisata bahari, kukerta terintegrasi, rumah batin, halal, kampung Baru

\begin{abstract}
Kampung Baru is one of the villages in Pekanbaru city that has the potential to develop large marine tourism. Its strategic location on the coast of Siak River and has a cultural reserve "RumahBatin" makes Kampung Baru as one of the new destinations of future historical tourism. The existence of Kampung Baru as a tourist destination is still not well exposed so there needs to be a touch of Science and improvement to accelerate its development. The purpose of this activity is to accelerate the development of marine tourism in Kampung Baru Village, Pekanbaru City. The method used is a survey method to identify activities and counseling methods to convey Science to the community. The stages of the implementation of the activity are divided into three stages of preparation, implementation and evaluation. The results of a quick survey conducted, to accelerate the development of marine tourism activities in Kampung Baru through the socialization of halal certificates, making and dividing trash cans, making and enforcing plank boards, planting trees and vegetable seedlings and cleaning inner houses. The implementation of the activity is doing well and on target this can be seen from the community and village officials in supporting this activity. With the integrated KUKERTA (Community Service), the neglected tourism potential of Kampung Baru can be reappointed as a marine tourism. This leads to the fact that the touch of Science through integrated KUKERTA (Community Service) is able to accelerate the development of marine tourism in Kampung Baru.
\end{abstract}

Keywords: marine tourism, integrated community service, rumahbatin, halal, kampung Baru

To cite this article: Fauzi, M., E. Prianto., Budijono, I. Putra., M. F. Surez., \& Z. Murni. 2020. Penerapan iptek melalui kukerta terintegrasi guna mengakselerasi pengembangan wisata bahari di Kelurahan Kampung Baru, Kecamatan Senapelan, Kota Pekanbaru. Unri Conference Series: Community Engagement 2: 146-152 https://doi.org/10.31258/unricsce.2.146-152

\section{(C) 2020 Authors}

Peer-review under responsibility of the organizing committee of Seminar Nasional Pemberdayaan Masyarakat 2020 


\section{PENDAHULUAN}

Kampung Baru merupakan salah satu kelurahan yang terdapat di Kecamatan Senapelan, Kota Pekanbaru dengan luas \pm 37,03 ha, terdiri dari 4 RT dan 8 RW. Kelurahan Kampung Baru terletak di DAS Siak, secara administrasi berbatasan dengan Sungai Siak (sebelah utara), Padang Terubuk (sebelah selatan), Tirta Siak/Tampan (sebelah barat), dan Kampung Bandar (sebelah timur). Kelurahan Kampung Baru memiliki visi yaitu mewujudkan masyarakat yang berahlak dan bertaqwa kepada Tuhan Yang Maha Esa serta mempunyai daya saing menuju masyarakat yang maju. Sedangkan misinya yaitu melaksanakan pelayanan prima kepada masyarakat, melaksanakan program pemberdayaan masyarakat, menciptakan kondisi aman, tertib, dan kondusif serta mensukseskan program pemerintah Kota Pekanbaru.

Kelurahan Kampung Baru memiliki jumlah penduduk sebesar 6.773 jiwa terdiri dari $2.623 \mathrm{KK}$, dimana sebanyak 3.239 laki-laki dan 3.534 perempuan. Sebagian besar mata pencaharian masyarakat adalah sebagai pedagang dan nelayan. Kelurahan Kampung Baru memiliki potensi yang sangat besar khususnya dari sektor pariwisata dan perikanan. Pengembangan kedua sektor tersebut merupakan aset kelurahan yang sangat besar serta berpengaruh pada tingkat kemakmuran masyarakat.

Pengembangan sektor pariwisata sangatlah tepat di kelurahan ini karena keberadaan Kampung Baru berhubungan erat dengan sejarah berdirinya Kota Pekanbaru. Sebelum berdirinya Kota Pekanbaru seperti saat ini, Kelurahan Kampung Baru masih berupa "batin" (perkampungan). Masyarakat pada saat itu mendiami batin yang ada di Kampung Baru. Hingga saat ini situs sejarah berdirinya Kota Pekanbaru dapat dilihat pada rumah-rumah batin yang ada di Kelurahan Kampung Baru. Situs-situs sejarah ini masih berdiri namun keberadaanya belum terpublikasi dengan baik.

Dasar hukum pengembangan pariwisata yang sesuai dengan prinsip pengembangan adalah Undang-undang RI Nomor 10 Tahun 2009 tentang kepariwisataan pasal 6: Pengembangan kepariwisataan yang dilakukan berdasarkan asas sebagaimana yang dimaksud dalam pasal 2 yang diwujudkan melalui pelaksanaan rencana pembangunan kepariwisatan dengan memperhatikan keanekaragaman, keunikan dan kekhasan budaya dan alam, serta kebutuhan (https://jdih.kemenkeu.go.id). Salah satu negara di kawasan Asia Tenggara yang memiliki wisata bahari sungai yang juga sedang berkembang yakni Sungai Chao Phraya di Bangkok, Thailand. "Wisata sungai di negara ini menggunakan pendekatan budaya. Thailand menawarkan kegiatan menyusuri sungai dengan menggunakan sisi sejarah. Sepanjang sungainya diberi lampu sehingga pada malam hari masih dapat melihat bangunan-bangunan bersejarah ketika menyusuri sungai" (Kompas.com, 4 Desember 2012).

Keberadaan Kelurahan Kampung Baru di tepi sungai Siak menjadikannya sebagai objek wisata bahari (ecotourism) bagi sebagian besar masyarakat Kota Pekanbaru. Setiap hari banyak masyarakat yang menghabiskan waktunya untuk menikmati objek wisata di Sungai Siak khususnya di Jembatan Siak I. Dengan adanya situs sejarah "Rumah Batin" dan Sungai Siak ini menyebabkan Kampung Baru memiliki daya tarik tersendiri untuk destinasi wisata di Kota Pekanbaru. Menurut Suwantoro (2004) bahwa ada beberapa unsur pokok yang harus mendapat perhatian khusus guna menunjang pengembangan pariwisata di daerah tujuan wisata yang meliputi 5 unsur, yaitu: objek wisata dan daya tarik wisata, prasarana wisata, sarana wisata, infrastruktur dan masyarakat, lingkungan serta budaya. Pengembangan potensi daerah dengan sumberdaya tempatan melalui produk lokal dan wisata bahari (Wijayanti et al, 2020) termasuk yang menarik untuk dikembangkan.

Walaupun sarana dan prasarana untuk mendukung kegiatan wisata bahari yang dibangun pemerintah daerah namun keberadaannya masih perlu dilakukan pembenahan. Untuk itu upaya pengembangan wisata bahari di Kelurahan Kampung Baru perlu dilakukan melalui sentuhan ilmu pengetahuan dan teknologi (IPTEK). Dengan adanya sentuhan IPTEK ini, potensi yang ada dapat dioptimalkan sehingga dapat meningkatkan perekonomian masyarakat dan menjaga kelestarian budaya daerah.

Kelurahan Kampung Baru memiliki potensi parisiwsata yang cukup besar. Namun potensi tersebut saat ini belum termanfaatkan secara optimal. Potensi pariwisata yang ada saat ini adalah Cagar Budaya Rumah Batin Senapelan yang keberadaannya belum diketahui publik secara luas. Rumah batin ini merupakan salah satu saksi bisu lahirnya Kota Pekanbaru dan keberadaannya saat ini mulai diabaikan oleh masyarakat. Untuk melestarikan ruman bathin ini diperlukan sentuhan Iptek agar keberadaannya dapat diketahui masyarakat secara luas dan juga keberadaannya tetap lestari.

Dilihat dari posisinya, Kelurahan Kampung Baru terletak dipinggiran Sungai Siak, memiliki pemandangan yang eksotis dengan daya tarik tersendiri. Sejak lama Sungai Siak dijadikan sebagai salah satu objek wisata di Kota Pekanbaru, namun belum berkembang dengan pesat. Dengan adanya rumah batin ini, wisata bahari Sungai Siak dapat dipadukan menjadi satu sehingga menjadi lebih menarik. 
Potensi Sungai Siak yang cukup besar namun belum dioptimalkan dengan baik disebabkan karena banyaknya permasalahan yang menghalangi pengembangan wisata bahari. Permasalahan yang dapat diidentifikasi antara lain: pertama, belum adanya sertifikasi halal bagi pedagang, kedua, kurangnya kebersihan lingkungan Kampung Baru, ketiga, kurang petunjuk informasi objek wisata, keempat, kurang asrinya lingkungan akibat sedikitnya zona hijau di Kampung Baru dan kelima, kondisi rumah bathin yang kurang terawat. Upaya mengoptimalkan Kelurahan Kampung Baru menjadi desa wisata bahari kedepannya diperlukan terobosan untuk menyelesaikan permasalahan diatas. Agar akselerasi pengembangan wisata bahari terlaksana dengan baik maka diperlukan sentuhan IPTEK. Salah satunya melalui kegiatan KUKERTA terintegrasi dengan melibatkan dosen, mahasiswa, pemerintah desa dan masyarakat setempat.

Melihat potensi desa yang sangat besar tersebut Universitas Riau melalui kegiatan KUKERTA terintegrasi pada tahun 2020 ini mencoba memberi sentuhan IPTEK guna mengoptimalkan potensi desa di Kampung Baru. KUKERTA terintegrasi merupakan program kegiatan yang mensinergikan antara kegiatan Pengabdian Kepada Masyarakat antara dosen dengan mahasiswa KKN guna mengaselerasi percepatan pembangunan di wilayah pedesaaan. Kegiatan KUKERTA terintegrasi yang dilaksanakan tahun 2020 berjudul "Edukasi Pembuatan Apartemen Ikan (Fish Aggregating Device) Untuk Meningkatkan Ekonomi Masyarakat Tempatan Di Kelurahan Kampung Baru Kecamatan Senapelan Kota Pekanbaru". Namun dalam pelaksanaannya ada beberapa kegiatan yang dapat diselaraskan dengan kegiatan ini dan mampu mentriger tumbuhnya kegiatan wisata bahari di Kelurahan Kampung Batu Kota Pekanbaru. Tujuan kegiatan ini adalah untuk mengakselerasi pengembangan wisata bahari di Kelurahan Kampung Baru Kota Pekanbaru.

\section{METODE PENERAPAN}

Pemberdayaan masyarakat melalui KUKERTA terintegrasi ini dilaksanakan pada bulan Juli-Agustus 2020 di Kelurahan Kampung Baru Kota Pekanbaru. Metode pelaksanaan kegiatan melalui metode survey dan metode penyuluhan. Metode survey dilakukan guna mendeskripsikan potensi yang ada dan menjabarkan kegiatakegiatan yang cocok untuk diterapkan sedangkan metode penyuluhan dilakukan guna menyampaikan IPTEK kepada masyarakat guna menyelesaikan masalah yang ada. Terkait permasalahan yang terjadi pada Kelurahan Kampung Baru Kota Pekanbaru sebagaimana telah diuraikan sebelumnya maka kegiatan pengabdian kepada masyarakat ini ditawarkan pada aparat Kelurahan dengan tahapan pelaksanaan kegiatan sebagai berikut, tahapan pelaksanaan kegiatan sesuai yang disampaikan Fauzi et al, 2020 yaitu:

\section{Tahap Persiapan}

Pada tahapan ini tim KUKERTA melakukan koordinasi dengan lurah dan jajarannya guna menyampaikan rencana kegiatan, sasaran, target yang akan dicapai serta mengidentifikasi potensi wilayah dan kegiatan yang perlu dilakukan.

\section{Tahap Pelaksanaan}

Terdiri dari beberapa tahap yaitu pemberian materi melalui penyuluhan, aksi bersih dan penanaman serta membangun sarana dan prasarana pendukung kegiatan wisata bahari.

\section{Tahap Evaluasi}

Monitoring dilakukan setiap selesai tahapan (hari pertama dan hari kedua). Evaluasi dilakukan sejalan dengan monitoring sehingga jika ada kekeliruan dan kendala dapat segera diatasi.

\section{HASIL DAN KETERCAPAIAN SASARAN}

\section{Tahap Persiapan}

Pada tahapan ini tim KUKERTA mempersiapkan seluruh keperluan selama pelaksanaan kegiatan seperti mengidentifikasi kegiatan guna mendukung pengembangan potensi desa, penyusunan jadwal agenda, modul materi pendampingan, persiapan sarana dan prasarana, koordinasi lapangan, sosialisasi dengan mengumpulkan pihak yang terlibat. Pada tahap persiapan ini tim KUKERTA secara intensif melakukan diskusi dengan aparat kelurahan, survey cepat dan merumuskan rencana kerja selama kegiatan ini berlangsung.

Berdasarkan hasil survey, guna mendukung pengembangan wisata bahari di Kampung Baru Kota Pekanbaru terdapat enam kegiatan yang perlu dilakukan. Kegiatan-kegiatan tersebut dapat dilihat pada Tabel 1 . 
Tabel 1. Jenis kegiatan yang diterapkan pada KUKERTA terintegrasi di Kampung Baru Kota Pekanbaru

\begin{tabular}{cllc}
\hline No. & \multicolumn{1}{c}{ Jenis Kegiatan } & \multicolumn{1}{c}{ Manfaat } & $\begin{array}{c}\text { Target Waktu } \\
\text { Pelaksanaan }\end{array}$ \\
\hline 1. & Sosialisasi sertifikasi halal & $\begin{array}{l}\text { Meningkatkan pamahaman pentingnya } \\
\text { jaminan produk halal dan meningkatkan } \\
\text { minat pembeli }\end{array}$ & 1 hari \\
2. & $\begin{array}{l}\text { Pembuatan dan pembagian } \\
\text { tempat sampah }\end{array}$ & $\begin{array}{l}\text { Meningkatkan dan menjaga kebersihan } \\
\text { lingkungan disekitar Kampung Baru }\end{array}$ & 1 minggu \\
3. $\begin{array}{l}\text { Pembuatan dan menegakan } \\
\text { papan plang (jalan, objek } \\
\text { wisata, nama ketua RT dan } \\
\text { RW) dan sebagainya }\end{array}$ & $\begin{array}{l}\text { Menambah informasi bagi masyarakat dan } \\
\text { memudahkan penyampaikan informasi }\end{array}$ & 1 minggu \\
4. $\quad \begin{array}{l}\text { Penanaman bibit pohon } \\
\text { 5. }\end{array}$ & $\begin{array}{l}\text { Mendukung program penghijauan dan } \\
\text { menambah keindahan serta keasrian }\end{array}$ & 2 hari \\
& $\begin{array}{l}\text { lingkungan } \\
\text { Meningkatkan minat keluarga untuk } \\
\text { menanam sayuran disekitar perkarangan } \\
\text { rumah }\end{array}$ & 1 hari \\
6. & $\begin{array}{l}\text { Pembersihan pekarangan } \\
\text { cagar budaya rumah batin }\end{array}$ & $\begin{array}{l}\text { Menjaga keindahan dan kelestarian cagar } \\
\text { budaya }\end{array}$ & 3 hari \\
\hline
\end{tabular}

Secara umum pencanangan sungai Siak sebagai objek wisata Kota Pekanbaru sudah lama dilakukan oleh Pemerintah Daerah, namun demikian pemerintah lebih fokus kepada pembangunan sarana dan prasarana fisik saja. Untuk pengembangan wisata bahari tidak hanya sarana dan prasarana fisik saja namun perlu juga dibangun pula mental guna membentuk karakter masyarakat. Sehingga budaya bersih, sopan-santun, ramah dan peduli juga tertanam didalam jiwa masyarakat. Selain itu untuk membentuk karakter mental yang lebih baik diperlukan pula proyek percontohan masing-masing kegiatan KUKERTA terintegrasi.

\section{Tahap Pelaksanaan}

Pada tahapan ini, tim KUKERTA terintegrasi mencoba melaksanakan kegiatan yang sudah teridentifikasi sesuai dengan target waktu yang telah ditentukan. Ketepatan waktu dan sasaran kegiatan merupakan tujuan utama yang ingin dicapai oleh tim, sehingga tim harus bekerjasama dengan aparat kelurahan dan masyarakat. Proses pelaksanaan masing-masing kegiatan diuraikan sebagai berikut.

Sertifikasi halal untuk setiap usaha kecil-menengah saat ini menjadi perhatian serius pemerintah. Kedepannya sertifikasi halal ini menjadi wajib bagi setiap pelaku usaha, untuk itu guna mendorong pembangunan wisata bahari di Kampung Baru maka sertifikasi halal merupakan sesuatu yang mutlak (Destiana dan Astuti, 2019; Ferdiansyah et al, 2020). Untuk memberi pengenalan terkait sertifikasi halal, tim KUKERTA terintegrasi memberikan materi halal kepada masyarakat khususnya para pedagang. Materi yang diberikan terkait pentingnya sertifikasi halal, manfaat, prosedur pengurusan hingga bagaimana teknis penyusunan dokumen halal tersebut. Metode penyampaian materi dilakukan melalui ceramah dan tatap muka langsung didalam ruangan. Masyarakat sangat antusias mengikuti penyuluhan sertifikasi halal, hal ini dapat dilihat dari diskusi yang berlangsung. Sebagian peserta merespon kegiatan sosialisasi ini dengan baik dan bahkan ada yang berminat untuk mengurusnya. 


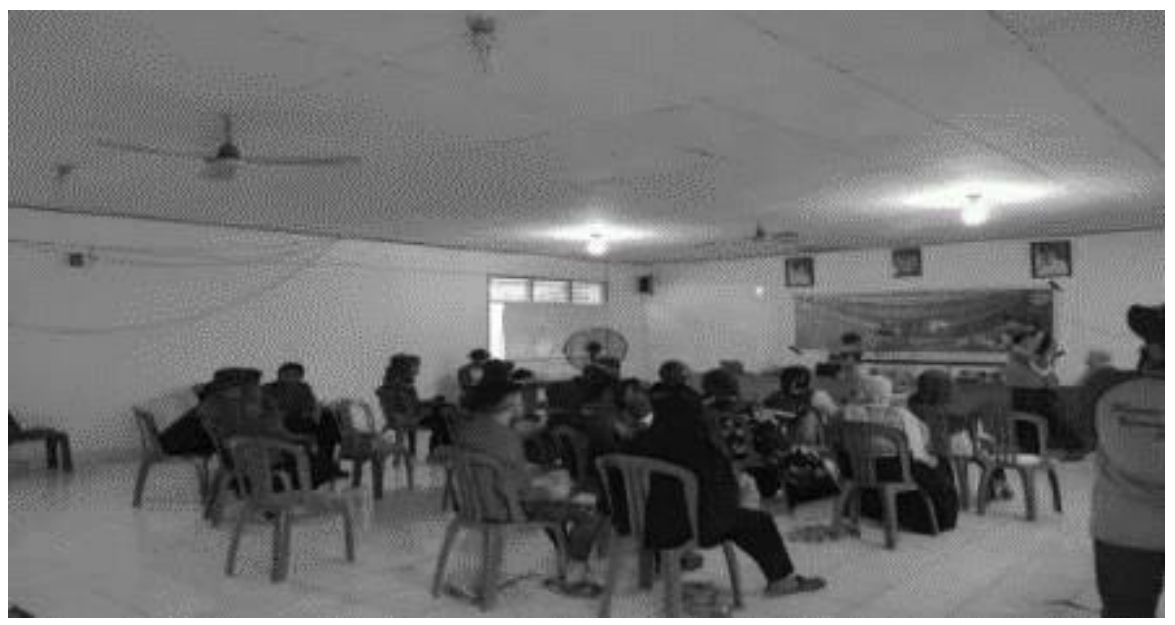

Gambar 1. Penyuluhan Sosialisasi Sertifikasi Halal di Kantor Kelurahan Kampung Baru

Untuk menjaga kebersihan dan keindahan lingkungan Kampung Baru kegiatan bersih desa dan penanaman pohon dilakukan melalui gotong royong dengan masyarakat. Pada kesempatan ini tim KUKERTA terintegrasi membuat dan membagikan tempat sampah kepada masyarakat agar masyarakat tidak membuang sampah sembarangan. Pada momen ini pula, tim KUKERTA terintegrasi dan masyarakat menanam pohon (kelor, gaharu dan buah-buahan) serta sayur mayur. Pohon-pohon yang ditanam tersebut merupakan bantuan dari Dinas Kehutanan dan Lingkungan Hidup Kota Pekanbaru. Penanaman pohon-pohon dan sayur mayur ini diharapkan dapat menjadikan lingkungan Kelurahan Kampung Baru lebih indah dan asri serta kedepannya pohon buah yang ditanam dapat bermanfaat bagi masyarakat sekitarnya. Kondisi lingkungan yang bersih, sehat dan asri ini akan menjadi daya tarik tersendiri untuk meningkatkan minat wisatawan lokal untuk berkunjung. Mengingat saat ini Kota Pekanbaru sangat minim memiliki objek wisata alam yang asri sehingga adanya wisata bahari di Kampung Baru ini dapat menarik masyarakat lokal untuk berkunjung.

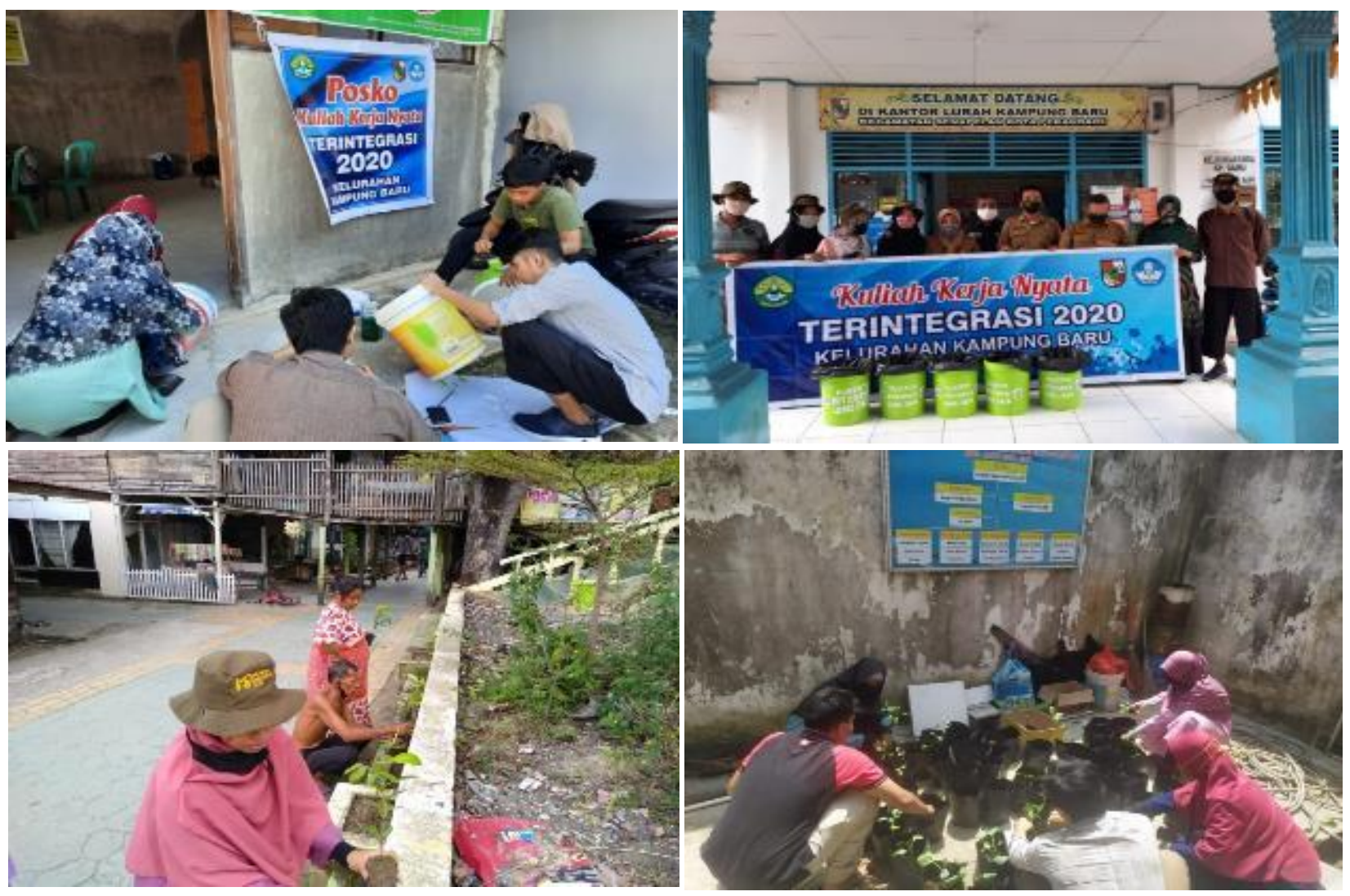

Gambar 2. Kegiatan pebuatan tempat sampah, penempatan bibit di polibag dan penanaman pohon 
Untuk memudahkan masyarakat mengenal dan mengetahui cagar budaya, maka tim KUKERTA terintegrasi membuat plang nama. Plang nama yang buat adalah nama jalan, rumah ketua RT dan RW, tanda arah menuju rumah batin dan lain sebagainya. Adanya plang nama ini akan memudahkah masyarakat yang ingin mengunjungi rumah batin dan lokasi wisata lainnya. Hal yang terpenting dari kegiatan ini adalah pembersihan rumah batin baik didalam maupun diluarnya. Kondisi rumah batin yang ada saat ini masih baik dan terawat namun demikian secara berkala rumah tersebut harus dibersihkan dan ditata agar lebih bersih dan menarik. Tim KUKERTA terintegrasi mencoba membersihkan lingkungan sekitar rumah batin ini menjadi lebih bersih. Disamping itu, dengan adanya aksi bersih dari tim KUKERTA terintegrasi ini dapat memberikan efek psikologis kepada masyarakat sekitar tentang pentingnya menjaga situs sejarah sebagai warisan nenek moyang dahulunya.
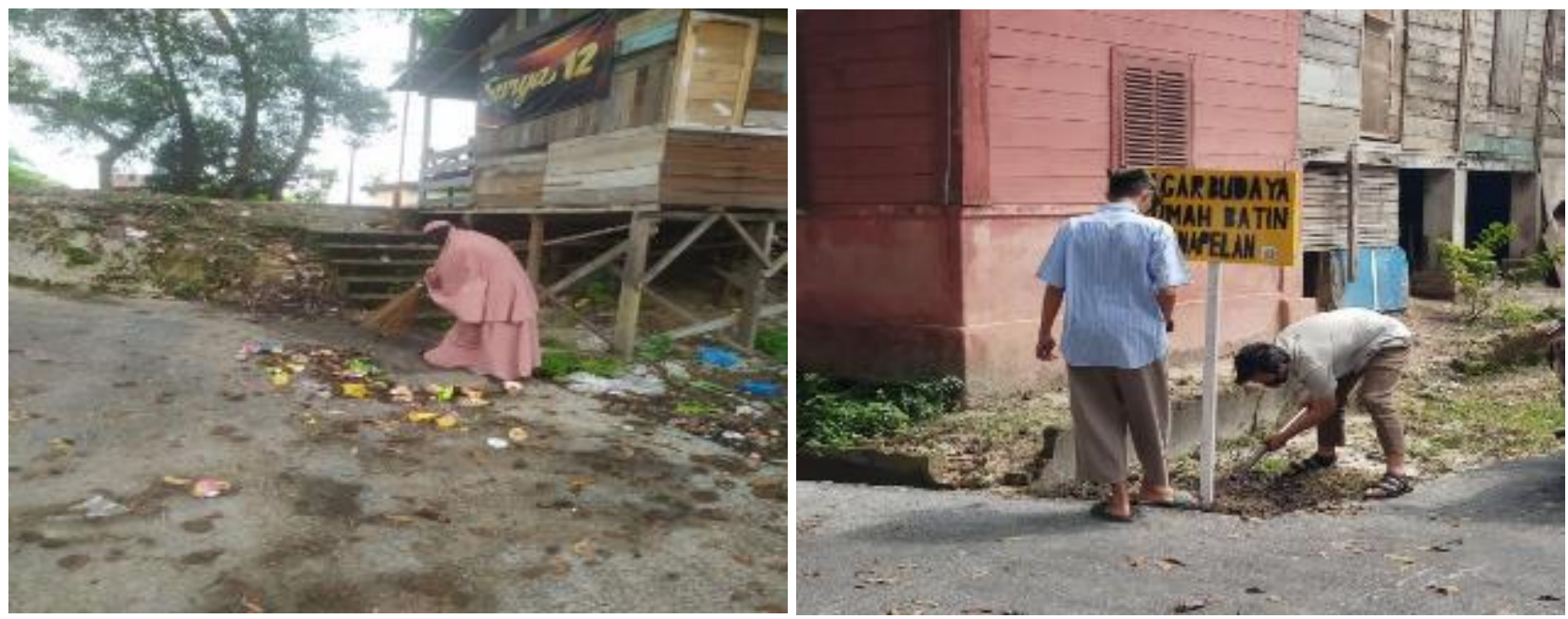

Gambar 3. Perbersihan perkarangan dan pembuatan plang nama Rumah Batin

Adanya kegiatan KUKERTA terintegrasi ini dinilai mampu memberikan perubahan yang cukup signifikan terhadap kehidupan masyarakat di Kelurahan Kampung Baru. Walapun waktu pelaksanaan kegiatan cukup singkat namun perubahan didalam masyarakat mulai dirasakan seperti lingkungan mulai asri, kebersihan terjaga dan keberadaan cagar budaya mulai dikenal masyarakat. Hal ini juga seperti yang disampaikan oleh Fauzi et al. 2020 bahwa kegiatan pendampingan masyarakat dalam implementasi teknologi dapat meningkatkan pengetahuan, pemahaman dan perubahan dalam masyarakat.

\section{Tahap Evaluasi Kegiatan}

Pelaksanaan kegiatan untuk mengakselerasi pengembangan wisata bahari di Kampung Baru ini telah seluruh dilaksanakan dengan baik. Namun demikian, evaluasi kegiatan ini perlu dilakukan. Hasil evaluasi yang dilakukan tim KUKERTA terintegrasi dan Lurah beserta jajarannya dapat dilihat pada Tabel 2.

Tabel 2. Hasil Evaluasi Kegiatan Akselerasi Pengembangan Wisata Bahari di Kampung Baru

\begin{tabular}{ccll}
\hline No. & \multicolumn{1}{c}{ Jenis Kegiatan } & \multicolumn{1}{c}{ Indikator Ketercapaian } & \multicolumn{1}{c}{ Tolok Ukur } \\
\hline 1. & Sosialisasi sertifikasi halal & $\begin{array}{l}\text { Kesadaran peserta ada } \\
\text { peningkatan ditandai dengan } \\
\text { respon dalam bentuk tanya jawab } \\
\text { dan rasa ingin tahu mengenai } \\
\text { penyusunan sertifikasi halal }\end{array}$ & $\begin{array}{l}\text { Peserta menyadari arti } \\
\text { penting dari sertifikasi h }\end{array}$ \\
& & $\begin{array}{l}\text { Tim KUKERTA telah berhasil } \\
\text { membuat tempat sampah dan } \\
\text { membagikannya kepada } \\
\text { masyarakat }\end{array}$ & $\begin{array}{l}\text { Masyarakat membuang } \\
\text { sampah didalam tempat } \\
\text { sampah }\end{array}$ \\
& $\begin{array}{l}\text { Pembuatan dan pembagian } \\
\text { tempat sampah }\end{array}$ & &
\end{tabular}


3. Pembuatan dan menegakan papan plang (jalan, objek wisata, nama ketua RT dan RW) dan sebagainya

4. Penanaman bibit pohon

5. Penanaman bibit sayuran

6. Pembersihan pekarangan cagar budaya rumah batin
Papan plang nama jalan, objek wisata, nama ketua RT da RW telah dibuat

Masyarakat secara antusias bergotong royong menanam pohon dilingkungan kelurahan

Masyarakat secara antusias bergotong royong menanam sayur dilingkungan kelurahan

Perkarangan cagar budaya menjadi lebih asri dan bersih
Masyarakat saat ini lebih mudah mendapatkan informasi lokasi wisata, rumah RT dan RW serta nama jalan

Masyarakat menyadari pentingnya program penghijauan

Masyarakat menyadari pentingnya manfaat menanam sayuran

Masyarakat menyadari pentingnya melestarikan cagar budaya

\section{KESIMPULAN}

Penerapan Iptek melalui kegiatan KUKERTA terintegrasi mampu mengakselerasi pengembangan wisata bahari di Kampung Baru Kota Pekanbaru. Pada pelaksanaan pengabdian masyarakat dan Kukerta terintergrasi dari Lembaga Penelitian dan Pengabdian Universitas Riau tahun 2020 mendapatkan bahwa ada enam kegiatan perlu dilakukan untuk mengakselerasi pengembangan wisata bahari diantaranya sosialisasi sertifikasi halal, membuat dan membagikan tempat sampah, membuat plan nama, menanam pohon, menanam sayuran dan membersihkan cagar budaya "Rumah Batin. Kegiatan ini telah berhasil dilaksanakan dengan baik dan memberikan pengaruh positif kepada masyarakat.

\section{UCAPAN TERIMA KASIH}

Penulis mengucapkan terima kasih kepada Lurah dan Masyarakat Kampung Baru Kecamatan Senapelan Kota Pekanbaru yang telah memfasilitasi pelaksanaan pengabdian pada masyarakat dan Kuliah Kerja Nyata (Kukerta 2020) terintegrasi untuk peningkatan pengetahuan dan perubahan perilaku bagi masyarakat dan nelayan. Serta diucapkan terima kasih kepada Lembaga Penelitian dan Pengabdian Kepada Masyarakat (LPPM) Universitas Riau yang menyandang dana melalui DIPA Pengabdian Kepada Masyarakat tahun 2020.

\section{DAFTAR PUSTAKA}

Ayuningtyas, R.A \& Djoefan, S. H. 2010. Strategi Pengembangan Pariwisata Di Sepanjang Sungai Kapuas Kota Pontianak. Jurnal Perencanaan Wilayah dan Kota, 10(1), 1-13.

Destiana, R \& Astuti, R. S. 2019. Pengembangan Pariwisata Halal Di Indonesia. Collaborative Governance dalam Pengembangan Pariwisata di Indonesia. Prosiding, 1(1), 331-353.

Fauzi, M., Sumiarsih, E., Adriman, A., Rusliadi, R., \& Hasibuan, I. 2020. Pemberdayaan masyarakat melalui pelatihan pembuatan ecobrick sebagai upaya mengurangi sampah plastik di Kecamatan Bunga Raya. Riau Journal of Empowerment, 3(2), 87-96. https://doi.org/10.31258/raje.3.2.87-96

Ferdiansyah, H., Endyana, C., Rachmat, H \& Khadijah, U. L. S. 2020. Pengembangan Pariwisata Halal di Indonesia Melalui Konsep Smart Tourism. Tornare - Journal of Sustainable Tourism Research, 2(1), 30 - 34.

Kompas.com, 4 Desember 2012. https://sains.kompas.com/read/2012/12/04/11595759/ayo.optimalkan.wisata.sungai.dan.danau . Di Unduh tanggal 25 September 2020.

https://jdih.kemenkeu.go.id/fullText/2009/10TAHUN2009UU.HTM. Diunduh 26 September 2020.

Suwantoro, G. 2004. Dasar-Dasar Pariwisata. Penerbit Jogjakarta: Andi.

Wijayanti, S., Harnadi, A., Putra, P., Sayagiri, T., Thomas, A., \& Frederich, W. 2019. Muaragembong: Potensi alam dan olahan Dodol Pidada dalam video dokumenter. Riau Journal of Empowerment, 2(1), 1-8.

https://doi.org/10.31258/raje.2.1.18 